\title{
Information and computing spaces integration for operating enterprises of pipeline systems using "ANGARA" computer technology"
}

\author{
Aleksandr V. Alekseev ${ }^{1, \dagger}$, and Nikolay N. Novitsky ${ }^{1}$ \\ ${ }^{1}$ Melentiev Energy Systems Institute of Siberian Branch of the Russian Academy of Sciences (ESI \\ SB RAS), Pipeline Energy Systems Department, 130, Lermontov str., Irkutsk, Russia, 664033
}

\begin{abstract}
The article describes the informatization level of enterprises operating pipeline networks. Existing problems are presented. These problems are related to the fragmentation of information systems and the inability to provide information support for decision-making on the management of the development and operation of pipeline systems. An overview of the most high-usage used software for automate the activities of enterprises is given. The need to create a common information space of an enterprise and the opportunities it provides is shown. A brief description of the information-computer environment "ANGARA" and the technology of organizing a common information space on its basis is given. The experience of practical application of the information-computer environment "ANGARA" for creating the common information space of the Municipal Unitary Enterprise "Vodocanal" in Irkutsk is cited. On the diagram of the organizational structure of the enterprise the workplaces with access to a common information is showed.
\end{abstract}

\section{Introduction}

Most of domestic operating enterprises and organizations have a "focal" nature of informatization. In separate subdivision and services of the unified organization, independent, disparate databases (DBs) and information systems are created that are related to the same object (pipeline system) of operation, control or design. As a result, there is a duplication of information in different databases, its inconsistency, unproductive efforts for its support and coordination both in different databases and in different departments of the organization. At the same time many important data for decision-making is absence or doubtful. The problem solving of "focal" automation lies in the plane of creating of the common information space of the enterprise (CISE), which provides the opportunity for rapid access for all services and specialists to any information available at the enterprise. Thus, one of the primary goals in the field of informatization of operational enterprises should be the origination of the CISE. Taking into account the emerging trends towards intellectualization and integration of pipeline networks, the development of the CISE is a necessary condition for the application of new management concepts.

\footnotetext{
${ }^{*}$ The research was carried out within the project III.17.4.3 of the Fundamental research program of SB RAS (AAAA-A17-117030310437-4) with finance support of RFBR and the Government of Irkutsk Region in the framework of research project № 17-48-380021

${ }^{\dagger}$ Corresponding author: asanya@mail.ru
} 
The main objects of the common information space [1] are: information resources databases, arrays of documents, all types of archives of schemes, project documents, etc. containing data recorded on appropriate media.

The CISE is designed to eliminate inconsistency, duplication of information, the need for parallel data support in various information systems (IS) by automatically synchronizing databases of various IS. This will reduce the organizational barriers between the various structural divisions of the enterprise (or between different enterprises) through the rapid exchange of electronic data, as well as reduce the time and labor costs for document circulation. Thus, it is possible to increase the controllability of the enterprise and the quality of the management decisions taken to develop and operate the pipeline systems.

The CISE should provide the following opportunities: 1) completeness of information about the pipeline system by integrating various information resources (cartographic, schematic, parametric, passports, operational, contractual, etc.); 2) accuracy of data - by eliminating its duplication or inconsistency, either through the principle of a "single data entry point" or by differentiating access rights; 3) availability - by providing on-line access to both enterprise specialists and external users of information in local or global network; 4) end-to-end information support for solving tasks of different territorial and temporal levels of management (automation, reconstruction, development, design, dispatching control, operation, e.t.c.) on a common information basis; 5) the flexibility of the development and application of the CISE $\neg$ by ensuring the possibility of integrating of new IP, updating or replacing existing ones. [2]

There are several software technologies for the CISE organization [3]:

- within a single software platform (for example, Microsoft products are integrated with each other via OLE / ActiveX / API tools);

- synchronization of databases of various IS;

- centralization of information through a single system, in which a complete set of all data is presented;

- organization of access to the information that is stored in distributed databases of different IS by means of their integration with each other (COM, CORBA, SOA, etc.).

Depending on the IS installed in the enterprise, the most appropriate technology or their combination is selected when organizing the CISE.

\section{Brief description of the current state of informatization of water utilities and existing software}

Enterprises operating pipeline engineering networks of cities usually have a number of IS such as billing systems (settlement systems with subscribers), financial and personnel management and accounting systems, geographic information system, CAD systems, telemetry systems (transmission of measured process parameters), passport systems, electronic design model, dispatching logs, etc. Each of these systems has its own data format. This so-called "focal" or "patchwork" automation leads to duplication and inconsistency of data, lack of access to the data for decision-makers on the control of pipeline systems.

Attempts to overcome such disunity are being made, and the need for the CISE organization is actively discussed, both by IT specialists [4-6] and by specialists in operational enterprises [7-10]. However, at the same time, the problem of CISE creating is often identified with the automation of document circulation in order to optimize the production and economic activities of enterprises (business processes). To date, a number of general purpose ISs for automating such processes (ECM - Enterprise Content Management) such as Documentum, Directum, Efrat, 1C: Document Management, Curator, etc. have been developed and implemented. 
In many water utilities universal software program are used to automate the activities of the entire enterprise. For example, Municipal Unitary Enterprise (MUE) "Vodokanal of St. Petersburg" and MUE "MosVodokanal" use a unified information system for the enterprise based on Oracle E-Business Suite (OEBS) technology [11] - a full-featured complex of integrated business applications of ERP II-class, other companies use SAP, 1C, Galaxy, Sail, Curator and so on. A brief description of them is given below.

OEBS is designed to automate the main activities of enterprises: the effectiveness of financial management, material flows, relationships with customers and suppliers, personnel, logistics, marketing, sales, maintenance and repair, and others. OEBS provides: transparency of business processes related to purchases and inventories; streamlining the planning of repairs and providing parts with spare parts and materials; improving the internal control of key business processes; improving the quality and reducing the time required for reporting. The system allows solving some technological problems; however it is not focused on the complex decision of technological control problems, has a high cost, both the software product and its implementation.

"1C Enterprise" [12], with various additional configurations ("1C: Enterprise 8. Vodokanal Management" or "1C: Enterprise 8. Technical Settlement Center of the Heating Network") provides management capabilities: production, finance, sales, purchases, storage (stocks), fixed assets and repairs, personnel and payroll, relations with customers and suppliers, monitoring and evaluation of the work of managers, monitoring and analysis of the activities of the enterprise, etc. Accounting for technological features of pipeline systems (PLS) are: equipment certification, calculation of losses in trunk and district networks, formation of water balance, automatic calculation of water supply and sewage reception and formation of payment documents in accordance with accepted calculation methods. The system "1C Enterprise" weakly takes into account the technological features of PLSs and does not have the possibility of their graphic display.

"Galaxy ERP" is a full-scale information system developed specifically for large and medium-sized enterprises in Russia and ex-USSR countries. It allows automating the activities of both the individual enterprise and the holding as a whole, being the basis of the CISE [13]. The main functional subsystems of the "Galaxy ERP" are: production management and planning, production asset management, financial planning, managerial accounting, tax and warehouse accounting, logistics management, personnel policy, security and comprehensive data analysis. In comparison with the "1C" "Galaxy ERP" system is oriented to larger enterprises and has fewer configuration options, and all improvements must be ordered from the developer, which is not always acceptable due to significant financial and time costs.

All mentioned and others ISs are classified as ERP and MRP categories and do not meet the requirements for the CISE. They are primarily aimed on business processes optimizing, automating workflow, accounting tasks, financial activities of an enterprise, statistical analysis and paying insufficient attention to technological processes of water supply and distribution, having only a few modules for solving specific technological problems.

\section{Formation of the CISE based on the information-computer environment "ANGARA"}

In the laboratory of pipeline and hydraulic systems of the Energy Systems Institute (ESI SB RAS, Irkutsk, Russia) the universal information and computing environment (ICE) "ANGARA" [14-19] was developed. It designed to automate the creation, support and use of electronic models of PLSs of various types and complexity in solving the applied problems of their research, design and operation within a common graphical user interface. ICE provides the following main features: 1) setting up the user's environment (configuring the 
structure, filling and integration of databases; 2) setting up the computing environment (integration of software and computational units and complexes); 3) application of this environment within the framework of a common graphical user interface for computer modeling of PLSs [19].

The result of the ICE configuration is the finite information and computing complexes for solving the PLS simulation problems. The obtained complexes frees the user from the need of knowledge of programming, calculation methods and mathematical modeling, allows solving substantive engineering tasks directly on the calculation schemes, using the usual concepts and objects. Thus, ICE provides the ability to create and work with a computer graphics model of real PLS of any type and purpose.

ICE "ANGARA" can potentially be used as a core, both when creating the CISE, and for its use in computer networks, while ensuring a relatively low cost of work for the integration of disparate subsystems of the automated process control system with automated industrial management system. In particular, due to the openness and extensibility of the databases, it is possible to integrate the database of ICE "ANGARA" with such IS as geographic information system, telemetry, commercial accounting, contractual conditions, etc. Such integration can be realized in the following ways: 1) creation of correspondence of records in tables of ICE "ANGARA" and adjacent ISs ("one to one" or "many to many"); 2) ICE inquires the relevant applications or their databases and writes the received information to it's own database or displays the necessary data on the screen according to the user request; 3) third-party applications transmit the data (when it appear or change) or request them from the ICE "ANGARA" database. Such automation can be carried out without the participation of ICE "ANGARA" developers.

\section{Experience of the CISE creation in MUE "Vodokanal" of Irkutsk city.}

When creating an automated workstation of dispatcher in MUE "Vodokanal" in Irkutsk [18,20], a prototype of the CISE for three types of PLS (water supply, sanitation and district heating) was made based on the ICE "ANGARA" (fig.1). IS "1C Enterprise 8. Management of the Vodokanal" and IS "Curator" had been installed at the company. As a result of the implementation the following capabilities were provided: 1) support (display, editing, activation, modeling, etc.) of different types of pipeline systems on a common cartographic basis; 2) updating of the geographic information (urban plan) from the monthly updated city GIS system; 3) updating data on contractual and actual loads of consumers, through integration with the ERP consumer work system "1C Enterprise"; access to other data on consumers (contracts, management companies, arrears, etc.); 4) integration with dispatching electronic journal (log) allows to maintain the current state of the valves in design schema; 5) integration with SCADA system allows using actual measured network parameters in hydraulic calculations; 6) obtaining data on real water consumption directly from accounting nodes by integration with billing systems; 7) storage of project documentation in the ICE "ANGARA" database; 8) carrying out various calculations using all the data available in the CISE (clauses 1-7), not only the data from the ICE "ANGARA" database [2].

The main difficulty in developing the CISE was to create a correspondence between the records in different IS. There is a discrepancy between the number of records in different databases, and the addresses and names of objects, which forces us to develop intermediate corresponding tables for data in different IS.

Figure 2 shows the organizational structure of MUE "Vodokanal" of Irkutsk city. To date, more than 30 workspaces (marked with hatching) have information support from the ICE "ANGARA". These are all specialists related to the technological process of water supply and sewerage. 


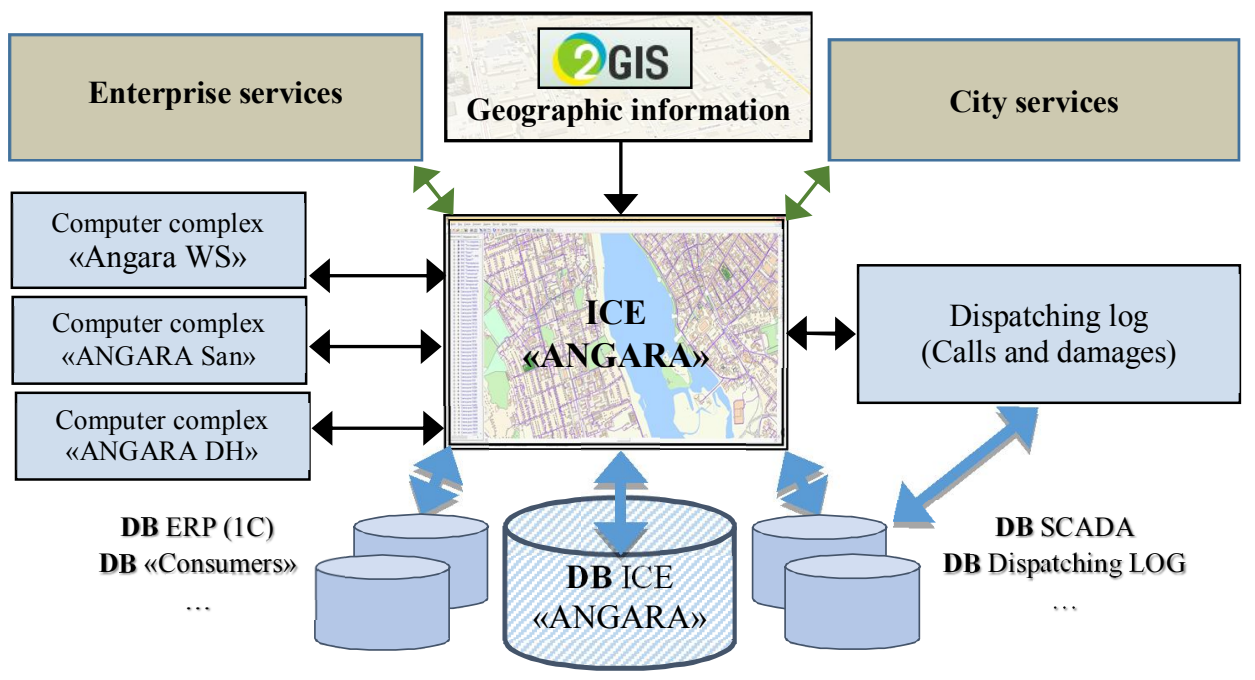

Fig.1. Organization of the CISE based on the ICE "ANGARA".

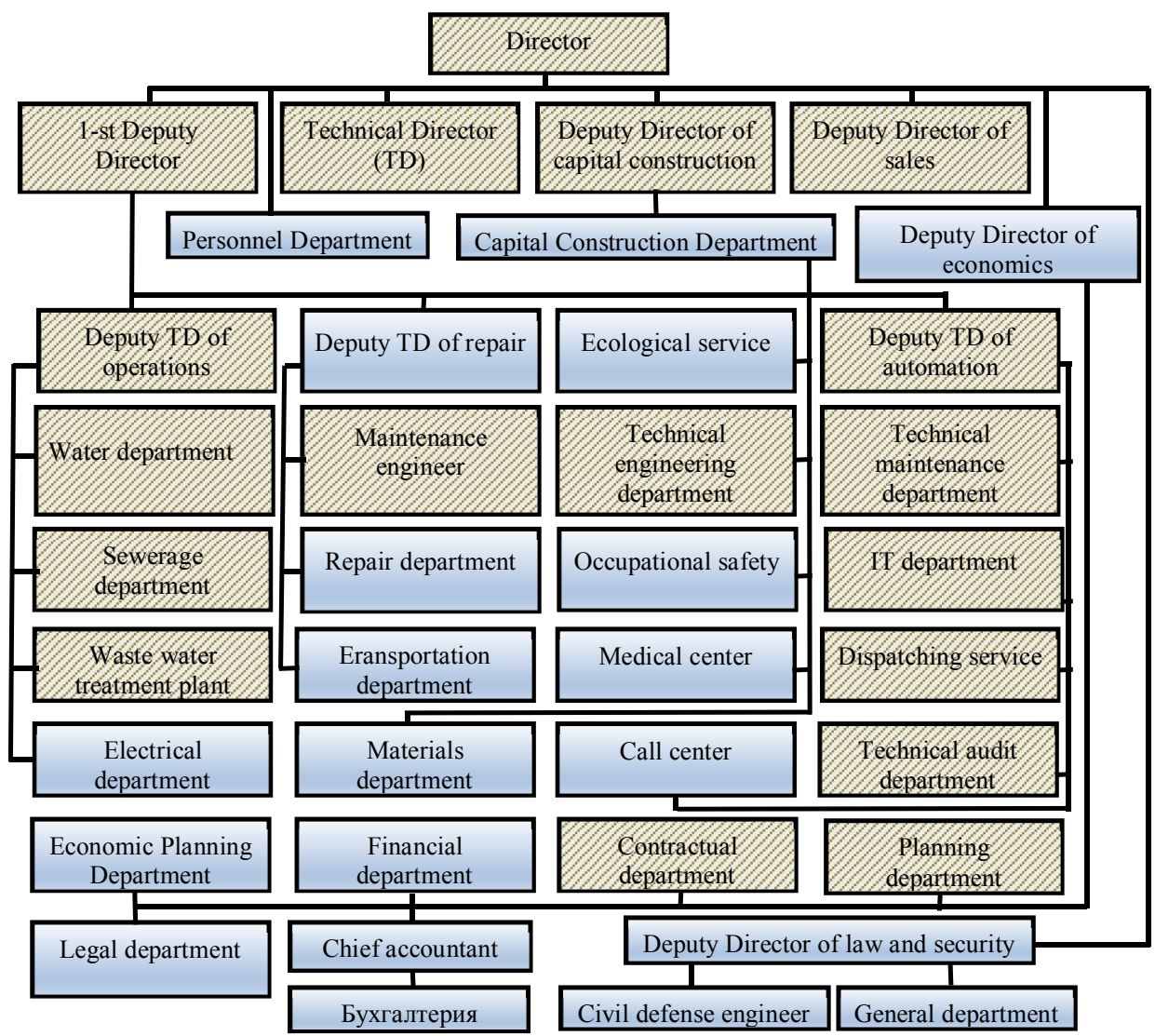

Fig.2. Organizational structure of the Municipal Unitary Enterprise "Vodokanal", Irkutsk.

Despite the fact that each department solves their own problems, all employees have access to a common, up-to-date information. For each employee, their access rights and the format of displayed information are asserted in accordance with its production tasks. In 
addition, a set of analytical functions of ICE "ANGARA" that simplifies the perception of large amounts of data is available to users.

\section{Conclusions}

The problem of "focal" automation of operating enterprises and the urgency of the CISE developing are disclosed. The definition, requirements, structure and methods of CISE organization are given. The most popular software tools for the CISE creating are presented. All these software products primarily automate business processes and give insufficient attention to informatization of technological processes taking place in the PLS and do not meet the requirements set by the CISE. A brief description of the ICE "ANGARA" and a scheme of the CISE creating on its basis are presented. An example of the CISE created in MUE "Vodokanal" of Irkutsk, is given. The organizational structure of the enterprise shows workplaces using CISE, including all necessary information about network and software packages for calculating and analyzing hydraulic operating conditions of water supply system.

\section{References}

1. http://lib.sale/pravo-grajdanskoe-uchebnik/informatsiya-gosudarstvo-edinoe.html

2. A.V. Alekseev, N.N. Novitsky, S.Yu. Obuzdin Water supply and sanitary technique 11, 54 (2017) [in Russian]

3. http://gridder.ru/technologies/computers/edinoe-informacionnoe-prostranstvopredprijatija-mif-ili-realnost/

4. A.V. Ostroukh, D.O. Gusenitsa, V.B. Golubkova, P.F. Yurchik IOSR-JCE 16/02, 31 (2014)

5. S. Oman, R. Leskovar, B. Rosi, A. Baggia Technical Gazette 24, 1889 (2017)

6. https://www.automationworld.com/article/technologies/erp/plm-mes-erp-closed-loopproduct-lifecycle

7. E.A. Melnik, M.M. Hyamyalyainen, S.V. Smirnova, M.Yu Yudin Water supply and sanitary technique 3, 20 (2012) [in Russian]

8. F.Yu. Kasatkin, S.V. Kostilyev Water supply and sanitary technique 6, 45 (2010) [in Russian]

9. A.V. Kritsky, D.C. Kargapoltsev, D.N. Brusnitsin, e.t.c. Water supply and sanitary technique 11, 45 (2015) [in Russian]

10. S.V. Hramenkov Water supply and sanitary technique 10, 3 (2011) [in Russian]

11. http://www.oracle.com/us/products/applications/ebusiness/overview/index.html

12. http://solutions.1c.ru/catalog/vodokanal/features

13. https://www.galaktika.ru/erp/funkcionalnost.html

14. N.N. Novitskiy, A.V. Alekseev the Eleventh International Conference Computing and control for the Water Industry. 3, 901 (2011)

15. N.N. Novitsky, M.G. Suharev, e.t.c. Pipeline systems of Energy (2015) [in Russian]

16. http://51.isem.irk.ru/angara

17. A.V. Alekseev, N.N. Novitsky, V.V. Tokarev, e.t.c. Pipeline systems of Energy, 221 (2007) [in Russian]

18. A.V. Alekseev, N.N. Novitsky, E.S. Melehov Proceedings of Irkutsk State Technical university 6,12 (2014) [in Russian]

19. A.V. Alekseev, N.N. Novitsky, Science bulletin of NSTU 2, 26 (2017) [in Russian]

20. A.V. Alekseev, N.N. Novitsky, S.Yu. Obuzdin Water supply and sanitary technique 11, 64 (2017) [in Russian] 